\title{
Trends in the incidence of childhood-onset diabetes in Europe 1989-1998
}

\author{
A. Green ${ }^{1}$, C. C. Patterson ${ }^{2}$ on behalf of the EURODIAB TIGER Study Group* \\ ${ }^{1}$ Department of Epidemiology and Social Medicine, University of Aarhus, Aarhus, Denmark \\ ${ }^{2}$ Queen's University Belfast, Belfast, UK
}

\section{Abstract}

Aims/hypothesis. To study the epidemiology of childhood-onset (Type I) insulin-dependent diabetes mellitus in Europe, the EURODIAB collaborative group in 1988 established prospective, geographically-defined registers of all children diagnosed with Type I diabetes under 15 years of age. This report is based on 24423 children, registered by 36 centres, with complete participation during the period 1989-1998 and representing most European countries with a population coverage of approximately 20 million children.

Methods. Multiple sources of ascertainment were used to validate the level of ascertainment. Trends in Type I diabetes incidence during the period were analysed using Poisson regression with the results from the 36 centres pooled into nine regions.

Results. The standardised average annual incidence rate of Type I diabetes varied more than tenfold between centres. Overall, the annual increase in inci- dence was $3.2 \%$ (95\%-CI: $2.7 \%, 3.7 \%$ ), being highest for children in the 0-4-year age-group $4.8 \%$ $(3.8 \%, 5.9 \%)$ and lowest for children in the 10-14year age group $2.1 \%(1.4 \%, 2.8 \%)$. However, the $a b$ solute increases in Type I diabetes were roughly similar in the three age-groups of 0-4, 5-9 and 10-14 years. Central Eastern Europe showed the highest increase whereas Sardinia and Northern Europe (except Finland) showed no evidence of an increase. For all age-groups relatively fewer cases had disease onset during the summer months, especially the 10-14-year age-group.

Conclusion/interpretation. The extremely large range of incidence rates within Europe has been confirmed. The incidence rate is generally increasing but is more pronounced in some regions than in others. Seasonality at disease onset is apparent even in the youngest agegroup. [Diabetologia (2001) 44 [Suppl3]: B3-B 8]

Keywords Type I diabetes, incidence, geography, secular trend, seasonality.
In a report presenting data from 1989-1990 from 26 registries in the EURODIAB Study Group, we showed that an exceptionally wide range of incidence rates for Type I diabetes exists within Europe [1]. New research and reviews, including the EURODIAB Study Group's recent report on the years 1989-1994, indicate that there has been a rapid increase in the incidence of Type I diabetes in many European countries in the last few decades with a higher

Corresponding author: Prof. Anders Green, Department of Epidemiology and Social Medicine, University of Aarhus, Vennelyst Boulevard 6, DK-8000 Århus C, Denmark

*see Acknowledgements rate of increase among children under 5 years of age [2-8]. This increase, in conjunction with the relatively low concordance rate in monozygotic twin pairs, highlights the importance of environmental factors [9-11].

This report, based on 10 years of prospective registration by the EURODIAB Study Group, updates the knowledge on the epidemiology of childhood diabetes in Europe. Particular attention is given to an analysis of age-specific, secular trends in different parts of Europe. 
Table 1. Summary of registration information for the 36 EURODIAB centres

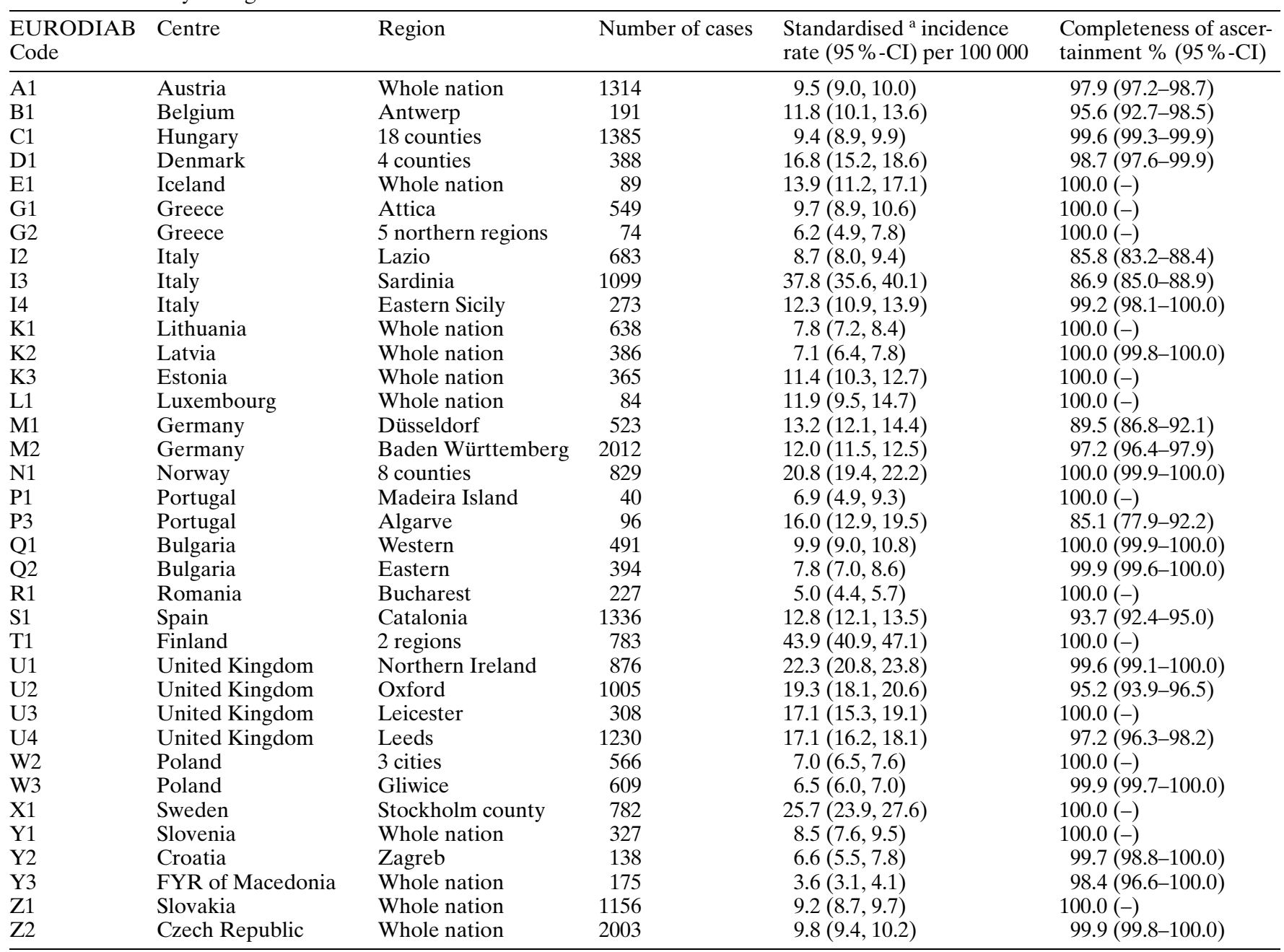

a The standard population assumes sex-groups and age-groups of equal size

\section{Methods and subjects}

The establishment of the EURODIAB collaborative group of childhood diabetes registers has been described previously in detail [1, 6, 12]. Briefly, in 1988 prospective registers of new cases of Type I diabetes among children aged under 15 years of age were established in 26 geographically-defined centres in Europe and Israel. Other centres whose registries fulfilled the specified quality criteria have since joined the group which expanded to comprise 44 centres in 1999. Many of the new participants are from the countries of Central and Eastern Europe so that most European countries are now represented.

Multiple sources of ascertainment were used to enable centres to assess their completeness of ascertainment. Capture-recapture methodology, which assumes that independent primary and secondary sources of ascertainment are available, was used to estimate the completeness of registration [13]. In most centres the primary source of ascertainment was hospital records or notifications by paediatricians and family doctors. Secondary sources varied depending on local circumstances but included social insurance schemes, diabetes associations and prescription data.

Type I diabetes was defined on the basis of a clinical diagnosis of idiopathic diabetes by a doctor. Cases occurring secondary to other conditions (e.g. in children who had been diag- nosed with cystic fibrosis or who had received high-dose steroid treatment) were excluded. The date of onset was taken as the date of the first insulin injection. Anonymous data were submitted to a Central Co-ordinating Office in Odense, Denmark, for data processing and analysis.

This analysis includes only those 36 centres with case registration during the complete 10-year period between 1989 and 1998 (Table 1). To analyse geographical variability and secular trends, the centres were grouped into nine regions. These were Finland; Sardinia; North Europe (rest): Danish, Norwegian and Swedish centres; Atlantic Europe: United Kingdom and Iceland centres; Baltic: Lithuanian, Latvian and Estonian centres; Central Western Europe: Austrian, Belgian, German, Luxembourg and Czech centres; Central Eastern Europe: Hungarian, Romanian, Polish and Slovakian centres; Mediterranean-Western Europe: Italian (excluding Sardinia), Portuguese and Spanish centres; Balkans: Greek, Bulgarian centres and centres from former Yugoslavia.

Annual estimates of the population size of each centre's geographically-defined area were used as denominators for the calculation of rates. Age and sex standardised incidence rates were obtained using the direct method with a standard population consisting of equal numbers of children in each of six subgroups defined by age $(0-4,5-9$ and $10-14$ years of age) and gender. 
Table 2. Summary of the Poisson regression analyses showing the incidence trend (overall and by age-groups) in geographical clusters during 1989-98 taking account of changes in population age/sex structure

\begin{tabular}{|c|c|c|c|c|}
\hline \multirow[t]{2}{*}{ Cluster } & \multicolumn{4}{|c|}{ Risk ratio (with $95 \%-\mathrm{CI}$ ) per annum } \\
\hline & Overall & $0-4$ & $5-9$ & $10-14$ \\
\hline Finland & $1.034(1.009 ; 1.059)^{\mathrm{b}}$ & $1.062(1.011 ; 1.115)^{\mathrm{a}}$ & $1.047(1.005 ; 1.091)^{\mathrm{a}}$ & $1.004(0.965 ; 1.044)$ \\
\hline Northern Europe (rest) & $0.998(0.983 ; 1.013)$ & $1.016(0.984 ; 1.049)$ & $0.989(0.964 ; 1.014)$ & $0.997(0.974 ; 1.021)$ \\
\hline Atlantic Europe & $1.039(1.027 ; 1.051)^{\mathrm{c}}$ & $1.042(1.016 ; 1.068)^{\mathrm{b}}$ & $1.062(1.041 ; 1.083)^{\mathrm{c}}$ & $1.019(1.001 ; 1.037)^{\mathrm{a}}$ \\
\hline Baltics & $1.029(1.010 ; 1.048)^{\mathrm{b}}$ & $1.026(0.982 ; 1.071)$ & $1.030(0.998 ; 1.062)$ & $1.030(1.002 ; 1.058)^{\mathrm{a}}$ \\
\hline Central Western Europe & $1.039(1.030 ; 1.048)^{\mathrm{c}}$ & $1.049(1.029 ; 1.069)^{\mathrm{c}}$ & $1.032(1.017 ; 1.047)^{\mathrm{c}}$ & $1.040(1.026 ; 1.054)^{\mathrm{c}}$ \\
\hline Balkans & $1.023(1.008 ; 1.038)^{\mathrm{b}}$ & $1.044(1.009 ; 1.080)^{\mathrm{a}}$ & $1.051(1.024 ; 1.078)^{\mathrm{c}}$ & $0.996(0.976 ; 1.017)$ \\
\hline
\end{tabular}

${ }^{\mathrm{a}} p<0.05^{\mathrm{b}} p<0.01^{\mathrm{c}} p<0.001$

Table 3. Summary of Poisson regression analyses of incidence trends for data from 36 centres considered in 9 regions

\begin{tabular}{|c|c|c|c|c|c|c|}
\hline \multirow[t]{2}{*}{ Model terms ${ }^{a}$} & \multicolumn{3}{|c|}{ Suitability of fit } & \multicolumn{3}{|c|}{ Likelihood ratio test for last term } \\
\hline & $\chi^{2}$ & df & $p$ & $\chi^{2}$ & df & $p$ \\
\hline 1 Base Model $^{\mathrm{b}}$ & 790.4 & 486 & $<0.001$ & - & - & - \\
\hline 3 Base Model $^{\mathrm{b}}+$ Year + Year $\cdot$ Region & 555.3 & 477 & 0.008 & 43.1 & 8 & $<0.001$ \\
\hline 4 Base Model $^{\mathrm{b}}+$ Year + Year $\cdot$ Region + Year $\cdot$ Age & 533.4 & 475 & 0.03 & 21.9 & 2 & $<0.001$ \\
\hline
\end{tabular}

a Age, Terms for age-groups 0-4, 5-9 and 10-14 years

Sex, Term for gender

Region, Terms for region (or centre group)

Year, Term for linear trend across the ten years

Poisson regression models were used to study differences in incidence rates between regions and to investigate trends in incidence rate. Models with terms for gender, age-group (0-4, 5-9 and 10-14 years), region and calendar year were fitted. These models provided a test for comparing incidence rates in the regions that took account of possible differences in the age and sex structure of the population. They also provided a test for linear trends within regions that took account of any changes in the age/sex structure of the population during the period of the study. Tests for departure from linear trend were also obtained. Further models incorporating interaction terms were used to test for differences in the linear trends between the regions, between the sexes and between the three agegroups. Likelihood-ratio chi-square tests were used to compare the fit of nested models and to provide a test of significance for the last term added to the model. Models were fitted using the SAS GENMOD procedure [14].

Roger's test was used for the analysis of seasonality at first insulin injection, grouping the cases as described above and adjusting for variations in the length of months by transforming the observations to months of equal length of $365 / 12$ days [15].

\section{Results}

Average Annual Incidence Rates. A summary of the information for each of the 36 participating centres is provided in Table 1 . The number of children with
Age $\cdot$ Sex, Terms for the interaction between age-group and gender

b Basemodel $=$ Constant + Age $+\mathrm{Sex}+\mathrm{Age} \cdot \mathrm{Sex}+\mathrm{Regi}-$ on + Age $\cdot$ Region + Sex $\cdot$ Region + Age $\cdot$ Sex $\cdot$ Region

Type I diabetes, the standardised average annual incidence rate and the estimated completeness of ascertainment are shown. The rates of completeness were high with all but four centres achieving over $95 \%$. The rates varied from 3.6 cases per 100000 personyears in Macedonia to 43.9 cases per 100000 in the Finnish centre. Overall, the incidence rates were high in Northern and North Western Europe and low in Central, Southern and Eastern Europe. However, Sardinia was a notable exception to this pattern with a much higher rate than any neighbouring country.

Analysis of trends in incidence rates. Estimates of trends in the incidence rate by region are shown in Table 2. When pooled over regions, the overall risk ratio per annum was $1.032(95 \%$-CI $1.027,1.037)$ giving an overall annual rate of increase of $3.2 \%$ (95\% CI $2.7 \%, 3.7 \%$ ). The corresponding age-specific increases were $4.8 \%(3.8 \%, 5.9 \%), 3.7 \%$ (2.9\%, $4.5 \%)$ and $2.1 \%(1.4 \%, 2.8 \%)$ for children in the age-groups $0-4,5-9$ and 10-14, respectively. The increase was particularly high in Central Eastern Europe whereas there was no statistically significant increase in Sardinia and Northern Europe (except Fin- 


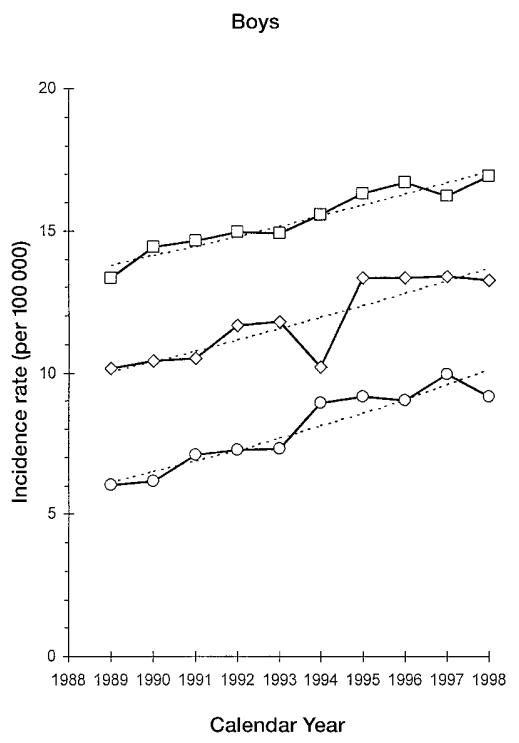

Fig. 1. Trends in age-specific incidence rates for boys and girls, pooled across regions. $-\bigcirc-, 0-4$ year age group; $\diamond-, 5-9$ year age group; $-\square-, 10-14$ year age-group

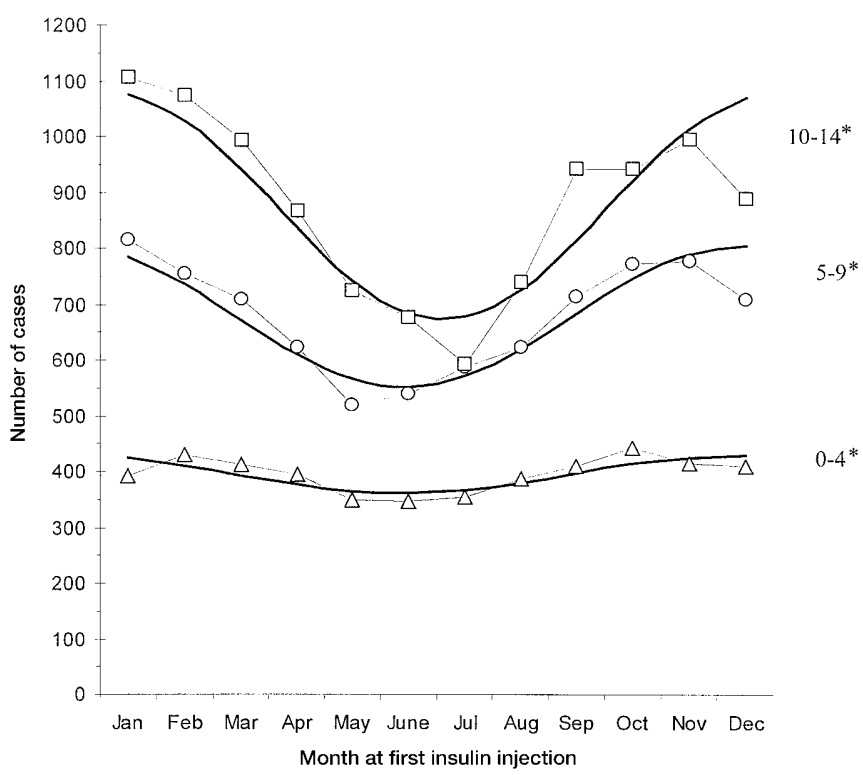

Fig. 2. Seasonality at first insulin injection by age-group (pooled analysis for all centres). $* p<0.001$ for seasonality

land). Central Western Europe was the only region in which there was evidence of non-linearity in the incidence trend over the period, with the annual rates suggesting a rapid initial increase during the first half of the period followed by a levelling off in the rate during the second half.

The results of fitting Poisson regression models to the entire dataset are summarised in Table 3. Preliminary model fitting confirmed that there were statistically significant differences in incidence rate between regions. A base model incorporating terms for age,

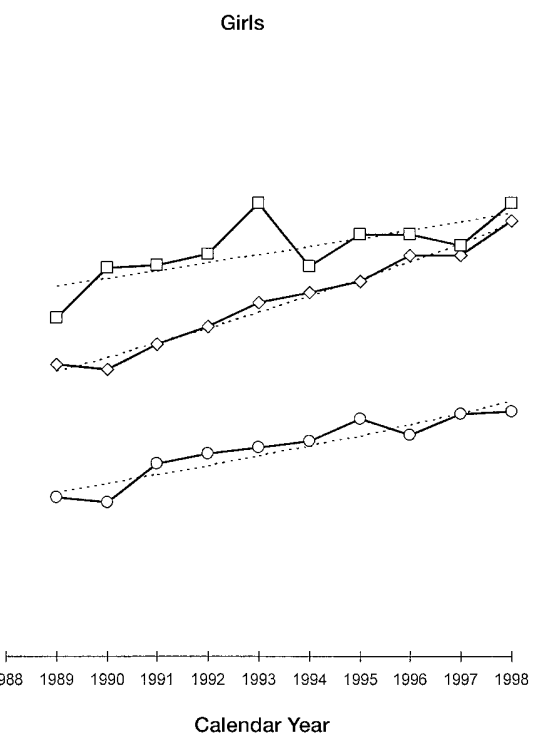

sex and region was therefore fitted to allow for differences in age-specific and sex-specific rates from region to region. Models specifying different patterns of linear trend were then obtained by adding terms to the base model. The test of the overall trend in incidence rate (shown in the second line of Table 3 ) is highly significant, however, as suggested by Table 2 , with a significant difference in the trends between regions (Table 3, third line). There is also evidence of a difference in the trends between age groups (Table 3 , fourth line), while there is no evidence that the trends differed between boys and girls (fifth line of Table 3 ), or that the differences in trends between age-groups depended on gender (Table 3, final line). Although even the most complex models showed some lack of fit, an adjustment for extra-Poisson variation in the regression model did not alter the conclusions. The age-specific annual rates pooled across centres are displayed for boys and girls within age-groups in Figure 1 . Whereas the relative increase was highest for the younger age-groups, the absolute increase was roughly similar in the three age-groups.

Analysis of seasonality at first insulin injection. The date of first insulin injection was known for all cases. The seasonality of first insulin injection followed a sinusoidal pattern for all three age groups (Fig.2). There was, however, more marked seasonality with increasing age (test of homogeneity between agegroups: $\left.\chi^{2}=46.48, d f=4, p<0.001\right)$. The corresponding amplitudes of oscillation were $+/-8,7 \%,+1$ $-19.8 \%$ and $+/-24.9 \%$ for the age-groups $0-4,5-9$ and 10-14 years, respectively. The trend was similar for boys and girls and for all regions (data not shown). 


\section{Discussion}

This 10-year analysis using standardised procedures confirms our previous findings that the range in incidence rate of childhood diabetes within Europe is greater than tenfold $[1,6]$. Such a magnitude of variation does not seem to be able to be explained by genetic differences, because Europeans (except for some outlying populations) are relatively homogeneous compared with the aborigines of other continents [16]. Furthermore, the rapid increase in incidence is probably not explicable in terms of shifts in the frequency of susceptibility genes but is probaly attributable to changes in environmental factors. The longer registration period has made it possible to study the incidence trends in detail. Overall, the incidence of childhood Type I diabetes in Europe is currently increasing at a rate of about $3 \%$, as has also been suggested in a recent literature review [4]. However, high-risk regions such as Sardinia and Northern Europe, excluding Finland, seem to have reached a plateau in incidence whereas Central Eastern Europe is currently experiencing a particularly rapid increase. It is tempting to speculate that factors associated with societal development could act as precipitators of childhood Type I diabetes, at least in some populations. Our results confirm that the increasing incidence is of particular concern for the youngest age-group. However, this only applies when increases in incidence are considered on a relative scale since the absolute increases in incidence are rather similar for all three age-groups.

This analysis of Type I diabetes confirms the wellknown pattern of seasonality at diagnosis. Because of the very large number of children included in this study it has been possible to demonstrate that children in the youngest age-group have a similar seasonal pattern to that of children in the older age-groups. However, our data also indicates an age effect, with most marked seasonality in children in the 10-14year age-group.

Continuous monitoring, using standardised procedures, will add to our knowledge of the geographical distribution and trends in incidence of Type I diabetes, thus providing the foundation for in-depth studies to test specific hypotheses and so gain a better understanding of the causes and pathogenesis of the disease.

\section{The EURODIAB Tiger Study Group}

Project Co-ordination: A. Green, Department of Epidemiology and Social Medicine, University of Aarhus, Denmark; G. Brutti, EURODIAB TIGER Coordinating Office, Odense University Hospital, Denmark.

Writing Committee: A. Green, Department of Epidemiology and Social Medicine, University of Aar- hus, Denmark; C.C. Patterson, Department of Epidemiology and Public Health, Queen's University Belfast, Northern Ireland.

Study Centre Leaders

Austria: E. Schober, Department of Paediatrics, University of Vienna. Belgium: I. Weets, C. Vandevalle, F. Gorus, M. Coeckelberghs, M. Du Caju, Belgian Diabetes Registry, Brussels. Hungary: G. Soltész, Department of Paediarics, University of Pécs. Denmark: B.S. Olsen, A.J. Svendsen, J. Kreutzfeldt, E. Lund, Department of Paediatrics, KAS-Glostrup. Iceland: A. V. Thorsson, Department of Pediatrics, University of Iceland, Reykjavik. Greece: C. Bartsocas, K. Kassiou, C. Dacou-Voutetaki, A.C. Kafourou, A. AlQadreh, C. Karagianni, Department of Pediatrics, National University of Athens; N. Papazoglou, General Hospital Agios Pavlos, Thessaloniki. Italy: P. Pozzilli, N. Visalli, L. Sebastiani, G. Marietti, R. Buzzetti, Biomedical University Campus, Rome; M. Songini, A. Casu, A. Marinaro, R. Ricciardi, M.A. Zedda, A. Milia, Department of Internal Medicine Hospital San Michele, Cagliari; F. Purrello, M. Arpi, G. Fichera, M. Mancuso, C. Lucenti, Department of Endocrinology, Garibaldi Hospital, Catania. Lithuania: B. Urbonaité, Institute of Endocrinology, Kaunas Medical Academy. Latvia: G. Brigis, Public Health and Epidemiology, Latvian Academy of Medicine, Riga. Estonia: T. Poodar, Hospital of Endocrinology, Tartu. Luxembourg: C. De Beaufort, Paediatric Clinic. Germany: G. Giani, J. Rosenbauer, Diabetes Research Institute, Düsseldorf; A. Neu, Tübingen Paediatric Clinic, Eberhard-Karls-Universität. Norway: G. Joner, Department of Community Health, Folkehelsa-Epidemiology, Oslo. Portugal: S. Abreu, Endocrinology Unit, Funchal Hospital Centre, Madeira; E. A. Pina, Department of Medicine, Faro District Hospital. Bulgaria: V. Christov, Endocrinology Clinic, University Alexandrov Hospital, Sofia; V. Tzaneva, V. Iotova, Department of Paediatrics, Clinic of Endocrinology, Medical University, Varna. Romania: C. Ionescu-Tirgoviste, Department of Nutrition and Metabolic Disease, University of Bucharest. Spain: A. Goday, Department of Endocrinology, Hospital del Mar, Barcelona. Finland: J. Tuomilehto, Diabetes and Genetic Epidemiology Unit, National Public Health Institute, Helsinki. United Kingdom: C.C. Patterson, R. Greenlees, D. Carson, D. Hadden, Metabolic Unit, Royal Victoria Hospital, Belfast; P. Bingley, Department of Medicine, Southmead Hospital, University of Bristol; N. Raymond, Department of Epidemiology and Public Health, University of Leicester; P.A. McKinney, H.J. Bodansky, C. Stephenson, Institute of Epidemiology and Health Services Research, University of Leeds. Poland: Z. Szybinski, Department of Endocrinology, Jagiellonian University, Krakow; P. Jarosz-Chobot, Department of Children's Endocrinology, Silesian School of Med- 
icine, Katowice. Sweden: G. Dahlquist, Department of Clinical Science, Paediatrics, University of Umeå. Slovenia: C. Krzisnik, T. Battelino, N. Bratina-Ursic, Endocrine, Diabetes and Metabolic Diseases, University Medical Centre, Ljubljana. Croatia: G. Roglic, Vuk Vrhovac Institute, Zagreb. Macedonia: M. Kocova, Paediatric Clinic, Medical Faculty, University of Skopje. Slovakia: D. Michalková, P. Hlava, M. Mikulecký, J. Črnay,1st Paediatric Clinic, University Komensky, Bratislava. Czech Republic: J. Vavrinec, 2nd Clinic of Paediatrics, Charles University, Prague.

Acknowledgements. This study has been supported in part by the European Community Concerted Action Programme (Grants BMH1-CT92-0043 and BMH4-CT96-0577).

\section{References}

1. Green A, Gale EAM, Patterson CC (1992) Incidence of childhood-onset insulin-dependent diabetes mellitus: the EURODIAB ACE Study. Lancet 339: 905-909

2. Bingley PJ, Gale EAM (1989) Rising incidence of IDDM in Europe. Diabetes Care 12: 289-295

3. Karvonen M, Tuomilehto J, Libman I, LaPorte R (1993) A review of the recent epidemiological data on the worldwide incidence of Type I (insulin-dependent) diabetes mellitus. Diabetologia 36: 883-892

4. Onkamo P, Väänäne S, Karvonen M, Tuomilehto J (1999) Worldwide increase in incidence of Type 1 diabetes - the analysis of the data on published incidence trends (1999) Diabetologia 42: 1395-1403

5. Karvonen M, Viik-Kajander M, Moltchanova E, Libman I, LaPorte R, Tuomilehto J for the Diabetes Mondiale (DiaMond) Project Group (2000) Incidence of childhood Type I diabetes worldwide. Diabetes Care 23: 1516-1526
6. EURODIAB ACE Study Group (2000) Variation and trends in incidence of childhood diabetes in Europe. Lancet 355: 873-876

7. Tuomilehto J, Virtala E, Karvonen M et al. (1995) Increase in incidence of insulin-dependent diabetes mellitus among children in Finland. Int J Epidemiol 24: 984-992

8. Gardner SG, Bingley PJ, Sawtell PA, Weeks S, Gale EAM, the Bart's-Oxford Study Group (1997) Rising incidence of insulin dependent diabetes in children aged under 5 years in the Oxford region: time trend analysis. BMJ 315: 713-717

9. Leslie RDG, Lo SSS, Hawa M, Tun RYM (1992) Lessons on the etiology of insulin-dependent diabetes from twin studies. In: Levy-Marchal C, Czernichow P (eds) Epidemiology and Etiology of Insulin-dependent Diabetes in the Young. Pediatr Adolesc Endocrinol vol. 21, Karger, Basel, pp 91-106

10. Kaprio J, Tuomilehto J, Koskenvuo M et al. (1992) Concordance for Type I (insulin-dependent) and Type II (non-insulin dependent) diabetes mellitus in a population based cohort of twins in Finland. Diabetologia 35: 1060-1067

11. Kyvik KO, Green A, Beck-Nielsen H (1995) Concordance rates of insulin dependent diabetes mellitus: a population based study of young twins. BMJ 311: 913-917

12. Levy-Marchal C, Patterson C, Green A, on behalf of the EURODIAB ACE Study Group (1995) Variation by agegroup and seasonality at diagnosis of childhood IDDM in Europe. Diabetologia 38: 823-830

13. Bishop YMM, Fienberg SE, Holland PW (1974) Discrete multivariate analysis: theory and practice. MIT Press, Cambridge, Massachusetts, pp 229-237

14. The SAS System for Windows (1996) Release 6.12. SAS Institute Inc., Cary, North Carolina

15. Roger JH (1977) A significance test for cyclic trends in incidence data. Biometrika 64: 152-155

16. Cavalli-Sforza LL, Piazza A (1993) Human genomic diversity in Europe: A summary of recent research and prospects for the future. Eur J Hum Genet 1: 3-18 